\begin{tabular}{|c|l|}
\hline Title & Outcome of Metastasectomy for Urothelial Carcinoma: A Multi-Institutional Retrospective Study in Japan \\
\hline Author(s) & $\begin{array}{l}\text { A be, Takashige; Kitamura, Hiroshi; Obara, W Wataru; Matsumura, Nagahide; Tsukamoto, Taiji; Fujioka, Tomoaki; Hara, } \\
\text { I sao; Murai, Sachiyo; Shinohara, Nobuo; Nonomura, Katsuya }\end{array}$ \\
\hline Citation & $\begin{array}{l}\text { Journal of Urology, 191(4), 932-936 } \\
\text { https://doi.org/10.1016/.juro.2013.11.004 }\end{array}$ \\
\hline Issue Date & 201404 \\
\hline Doc URL & http://hdl.handle.net/2115/56347 \\
\hline Type & article(author version) \\
\hline File Information & J Urol_191(4)_932-936.pdf \\
\hline
\end{tabular}

Instructions for use 


\section{Outcome of metastasectomy for urothelial carcinoma: A multi-institutional}

retrospective study in Japan.

Takashige Abe* ${ }^{1}$, Hiroshi Kitamura ${ }^{2}$, Wataru Obara $^{3}$, Nagahide Matsumura ${ }^{4}$, Taiji Tsukamoto $^{2}$, Tomoaki Fujioka ${ }^{3}$, Isao Hara ${ }^{4}$, Sachiyo Murai ${ }^{1}$, Nobuo Shinohara ${ }^{1}$, Katsuya Nonomura ${ }^{1}$

1 Department of Urology, Hokkaido University Graduate School of Medicine, Sapporo, Japan

2 Department of Urology, Sapporo Medical University School of Medicine, Sapporo, Japan.

3 Department of Urology, Iwate Medical University, Iwate, Japan.

4 Department of Urology, Wakayama Medical University, Wakayama, Japan.

*Address correspondence to: Takashige Abe, Department of Urology, Hokkaido University Graduate School of Medicine, North-15, West-7, North Ward, Sapporo 060-8638, Japan

Tel.: +81-11-7161161 Ext.5949 Fax: +81-11-7067853

E-mail: takataka@rrf6.so-net.ne.jp 
Word count: 1,384 words. 


\section{ABSTRACT}

Purpose: To determine prognostic factors associated with prolonged survival after metastasectomy for urothelial carcinoma (UC).

Materials and Methods: Forty-two patients who underwent resection of metastases of UC with curative intent at 4 different Japanese university hospitals were included. Most of the patients (41/42) underwent systemic chemotherapy before and/or after metastasectomy. Overall survival was analyzed using the Kaplan-Meier method, and the relationship between the clinical characteristics and survival was analyzed using the log-rank test.

Results: Details of metastasectomy were as follows: lymph node dissection $(n=20)$, pulmonary resection $(n=12)$, pelvic exenteration $(n=3)$, resection of local recurrence $(n=2)$, resection of subcutaneous metastasis $(n=2)$, liver resection $(n=1)$, and others $(n=2)$. The median overall survival time was 29 months (interquartile range [IQR]: 19-80 months) from the initiation of treatment for metastases and 26 months (IQR: 11-90) from metastasectomy. The overall 5-year survival rate from metastasectomy was $31 \%$. On univariate analysis, patients undergoing metastasectomy for solitary lung or solitary lymph node metastasis showed a significantly longer survival than the others undergoing metastasectomy (median survival time: 81 months in patients with solitary lung or solitary lymph node metastasis vs. 19 months in the others, log-rank test $\mathrm{p}=0.0296)$ 
Conclusions: Long-term cancer control could be achieved in a subgroup of patients undergoing metastasectomy, especially in those with solitary lung or solitary lymph node metastasis.

Key Words: urothelial carcinoma, metastatic urothelial carcinoma, metastases, metastasectomy 


\section{INTRODUCTION}

Systemic chemotherapy is the mainstay of treatment for metastatic urothelial carcinoma (UC). Although initial response rates are $50-70 \%^{1,2}$, these responses are usually transient. Long-term survival is achieved in only a small proportion of patients. In order to improve the outcome, several investigators have advocated the resection of metastases (so-called "metastasectomy") for surgical consolidation. ${ }^{3-10}$ For example, our group previously reported a median survival of 42 months in 12 patients undergoing complete resection of all detectable metastases, which was significantly longer than that of patients who did not undergo metastasectomy (10 months). ${ }^{6}$ However, its role and characteristics associated with long-term survival after metastasectomy remain undetermined.

The aim of this retrospective multi-institutional study was to examine the long-term outcomes and characteristics associated with prolonged survival after metastasectomy of UC. 


\section{MATERIALS AND METHODS}

Each institutional review board approved the retrospective review and analysis of metastatic UC patients undergoing metastasectomy during the study period. Between 1989 and 2012, 42 patients with metastatic UC underwent resection of metastasis at 4 different Japanese university hospitals. These surgeries were performed with a curative intent. Patients undergoing metastasectomy for symptom palliation were not included. Demographic, surgical, pathological, and follow-up data were retrospectively collected from medical charts. During the study period, all therapeutic decisions including the extent of lymph node dissection (LND) at the time of radical cystectomy or nephroureterectomy, indication of neoadjuvant or adjuvant chemotherapy, or the choice of the respective chemotherapy regimens at the development of metastasis, were left to the discretion of each attending doctor on the basis of individual disease characteristics and patients' requests. Regarding the indication of metastasectomy, we considered metastasectomy when patients had metastasis in a single organ with a small number of metastases, a good performance status, and showed a favorable response to chemotherapy, although we did not have strict prospective criteria. In a situation contrasting to the above-mentioned one (e.g., more than five lung metastases, several organ metastases), we considered second-line chemotherapy. Generally, the disease status was re-evaluated with a chest X-ray or chest $\mathrm{CT}$ scan and $\mathrm{CT}$ scan of the abdomen and pelvis every 3-6 months. In patients 
receiving systemic chemotherapy, tumor responses were assessed every two or three cycles by CT scan, although confirmation was not always carried out. Bone scans were conducted if symptoms were present.

Overall survival was analyzed from the initiation of treatment for metastatic UC or the time of metastasectomy until death or the last follow-up according to the Kaplan-Meier method, using the log-rank test to assess the significance of differences. The variables considered in survival analysis were sex (male vs. female), age ( $<68$ vs. 268), primary site (bladder only vs. others), disease-free interval between primary surgery and the development of metastases ( $<12$ vs. $\geq 12$ months, $<24$ vs. $\geq 24$ months), systemic chemotherapy before metastasectomy (yes vs. no), and metastatic sites (lymph node (LN) only vs. lung only vs. others, LN/ lung only vs. others, solitary LN / solitary lung metastasis vs. others). All calculations were performed using JMP ${ }^{\circledR}$ version 6.03 . P-values $<0.05$ were considered significant. 


\section{RESULTS}

Table 1 shows the patients' characteristics. The median patient age at the start of treatment for metastatic disease was 67.5 years (range: $36-80$ ). The primary tumor site was the bladder in 21 patients, upper urinary tract in 18 patients, and both in 3 patients. In this cohort, 39 patients had metastatic disease involving a single organ, while 3 had disease involving double organs at the presentation of metastases. The number of metastases was one in 23 patients, 2 or more in 14 patients, and uncountable due to aggregated metastatic LNs in 5 patients. Thirty-six patients developed metastasis after resection of the primary site, while 6 already demonstrated metastases at the diagnosis of primary cancer. In the present study, of the 8 patients with disease in the regional LNs, five patients developed regional LN recurrence after nephroureterectomy (pathological node status at nephroureterectomy, $\mathrm{pN} 0: \mathrm{n}=1, \mathrm{pN}+: \mathrm{n}=1, \mathrm{pNx}: \mathrm{n}=3$ ) and 1 after radical cystectomy (pathological node status at radical cystectomy, $\mathrm{pN} 0$ : $\mathrm{n}=1$ ). Of the remaining two patients, one had aggregated LN metastasis at the initial presentation and underwent LND at the time of nephroureterectomy after systemic chemotherapy with a complete response of lung metastasis, and the other patient underwent LND after salvage systemic chemotherapy, although LND had been discontinued at the time of nephroureterectomy after induction chemotherapy. The median disease-free interval between surgical resection of the primary cancer and the 
development of metastasis was 16 months (range: 0-103). All but one patient received systemic chemotherapy, and the dominant treatment course was "metastasectomy after systemic chemotherapy" $(n=34)$. Table 2 shows a summary of chemotherapy regimens used in the present cohort. In the present cohort, MVAC/ $\mathrm{MEC} / \mathrm{GC}$ regimens were used as induction chemotherapy in most of the patients. Paclitaxel or docetaxel-including regimens were performed in 21 patients as salvage therapy after induction chemotherapy, or for disease recurrence after cisplatin-based neoadjuvant or adjuvant chemotherapy. Finally, during the treatment course, 23 patients received at least two different chemotherapy regimens.

Table 3 presents a summary of metatstasectomy. No patient underwent biopsy before metastasectomy. The interval between the last systemic chemotherapy and metastasectomy $(n=34)$ was a median of one month (interquartile range [IQR]: 1-2.25), which suggested that a large proportion of patients had undergone metastasectomy immediately after systemic chemotherapy. LND (retroperitoneal LNs below aortic bifurcation: $\mathrm{n}=6$, retroperitoneal $\mathrm{LNs}$ above aortic bifurcation: $\mathrm{n}=9$, distant lymph nodes: $n=5)$ and pulmonary resection $(n=12)$ were frequent procedures in this cohort. Two patients underwent the simultaneous resection of primary cancer and metastasis after systemic chemotheapy (cervical LNs and initially unresectable abdominal LNs). The pathology demonstrated viable cancer in 30 patients. Only necrosis was detected in 12 of the 34 patients undergoing systemic chemotherapy before metastasectomy. 
There was no operative mortality. Seven patients underwent repeat metastasectomy.

Figure $1 \mathrm{a}$ and $1 \mathrm{~b}$ represent the Kaplan-Meier estimate of overall survival for all patients. The median overall survival time was 29 months (IQR: 19-80) from the initiation of treatment for metastases and 26 months (IQR: 11-90) from the metastasectomy. The overall 5-year survival rate from the metastasectomy was $31 \%$. Table 4 shows the results of univariate analysis for the prognostic significance after metastasectomy. Patients undergoing metastasectomy for solitary lung or solitary lymph node metastasis showed a significantly longer survival than the others undergoing metastasectomy (median survival time: 81 months in patients with solitary lung metastasis or solitary lymph node metastasis vs. 19 months in the others, Figure 1c, $\log$-rank test $\mathrm{p}=0.0296)$. 


\section{DISCUSSION}

In 1982, Cowles and colleagues were the fist group to report the surgical

outcomes in patients with pulmonary metastasis of UC. ${ }^{7}$ They reported a median survival of 5 years for 6 patients following surgical resection for solitary pulmonary metastasis of UC without systemic chemotherapy. Since their report, several investigators have reported survival outcomes after metastasectomy in patients with metatstatic urothelial carcinoma. ${ }^{3-6,8-10}$ For example, Siefker-Radtke et al. reported outcomes for 31 patients undergoing postchemotherapy resection of metastatic lung (77\%), brain (7\%), skin (3\%), and distal LNs (13\%). The median OS from the time of surgery was 23 months, and a 33\% 5-year OS rate was observed. ${ }^{3} \quad$ Lehman and colleagues reported outcomes in 44 patients from 15 different German centers, with distant metastases of UC, who underwent complete resection of all detectable metastases. The median OS from the time of resection was 27 months, and a $28 \%$ 5-year OS rate was observed. ${ }^{8}$ In the present study, we observed a similar result of a median OS of 26 months after metastasectomy. Our observations further support the possibility of long-term cancer control after metastasectomy.

The appropriate selection of patients for metastasectomy is essential if this approach is to be considered for general use. As described in Methods, in the present cohort, metastasectomy was considered in patients with limited single organ metastasis or in those with residual disease after a major response to systemic chemotherapy. 
Regarding the indication of metastasectomy, investigators described a similar opinion in their studies. Siefker-Radtke et al. indicated that their strategy was to consider metastasectomy in patients who responded to chemotherapy and showed recurrence at the initial or a single metastatic site, who had a tumor considered surgically resectable with clear margins, and showed a period of disease stability with no evidence of rapid progression (3-month observation interval between chemotherapy and metastasectomy), although these criteria were used as a general guideline and not an absolute requirement. 3 Lehmann stated that this therapeutic approach remains highly investigational and should only be offered to patients with relapse at a single site or at the initial site following chemotherapy, in whom complete resection of all detectable masses is feasible. ${ }^{8}$ Svatek et al. from the MD Anderson Cancer Center reported that their approach was to consider the surgical consolidation of visceral metastases for patients with a tumor at a single distant site who respond well to chemotherapy and show no evidence of rapid progression elsewhere. ${ }^{10}$ In the present univariate analysis, metastasectomy for solitary lung or solitary LN metastasis was significantly correlated with long-term cancer control (median survival time: 81 months in patients with solitary lung or solitary LN metastasis vs. 19 months in the other patients, log-rank test $\mathrm{p}=$ 0.0296). Kanzaki et al. also reported the same trend in the setting of surgical consolidation for lung metastases of UC, where the 5-year survival rate of patients with solitary metastasis was $85.7 \%$, while that of patients with multiple metastases was 
20.0\%. ${ }^{11}$ Taken together with these observations, clinicians should carefully select patients, considering the "stability", "spread", and "resectability" of metastatic disease. There was a negative report from Otto et al. in which the median survival time was 7 months after the surgical removal of metastases from bladder cancer refractory to systemic therapy. ${ }^{12}$

As described above, of the 8 patients with the disease in the regional lymph nodes, five patients developed regional LN recurrence after nephroureterectomy (pathological node status at nephroureterectomy, $\mathrm{pN} 0: \mathrm{n}=1, \mathrm{pN}+\mathrm{n}=1, \mathrm{pNx}: \mathrm{n}=3$ ) and 1 after radical cystectomy (pathological node status at radical cystectomy, pN0: $\mathrm{n}=1$ ). The extended LND approach at the time of primary surgery may prevent such recurrence. ${ }^{13,14}$

Our study was limited by the small sample size, heterogeneous cohort, retrospective nature, and diversity of treatment strategies. For example, our cohort included metastatic urothelial carcinomas derived from bladder and/or upper urinary tract together, which might have different biological behaviors regardless of the same histology. In addition, the timing of metastasectomy was not considered for study inclusion ( 8 patients received metastasectomy before and 34 patients underwent metastasectomy after systemic chemotherapy). The role of metastasectomy and selection criteria can only be definitively clarified with a well-controlled, prospective, randomized study. However, considering the global difficulty in the accrual of studies 
on advanced UC, most information still comes from retrospective analyses. We consider that several important findings were generated by our study. 


\section{CONCLUSIONS}

Long-term cancer control could be achieved in a subgroup of patients undergoing metastasectomy, especially in patients with solitary lung or solitary LN metastasis. 


\section{REFERENCES}

1. Sternberg CN, Yagoda A, Scher HI, et al: Preliminary results of M-VAC (methotrexate, vinblastine, doxorubicinand cisplatin) for transitional cell carcinoma of the urothelium. J Urol 1985;133: 403.

2. Scher HI: Should single agents be standard therapy for urothelial tract tumors? J Clin Oncol 1989; 7: 694.

3. Siefker-Radtke AO, Walsh GL, Pisters LL et al: Is there a role for surgery in the management of metastatic urothe- lial cancer? The M. D. Anderson experience. J Urol 2004; 171: 145.

4. Dodd PM, McCaffrey JA, Herr H et al: Outcome of post- chemotherapy surgery after treatment with methotrex- ate, vinblastine, doxorubicin, and cisplatin in patients. J Clin Oncol 1999; 17:2546.

5. Miller RS, Freiha FS, Reese JH et al: Cisplatin, methotrexate and vinblastine plus surgical restaging for patients with advanced transitional cell carcinoma of the urothelium. J Urol 1993; 150: 65.

6. Abe $\mathrm{T}$, Shinohara $\mathrm{N}$, Harabayashi $\mathrm{T}$ et al: Impact of multimodal treatment on survival in patients with metastatic urothelial cancer. Eur Urol 2007; 52: 1106.

7. Cowles RS, Johnson DE, McMurtrey MJ: Long-term results following thoracotomy for metastatic bladder cancer. Urology 1982; 20: 390.

8. Lehmann J, Suttmann H, Albers P et al: Surgery for metastatic urothelial carcinoma 
with curative intent: the German experience (AUO AB 30/05). Eur Urol. 2009; 55:1293.

9. Matsuguma $\mathrm{H}$, Yoshino $\mathrm{I}$, Ito $\mathrm{H}$ et al: Is there a role for pulmonary metastasectomy with a curative intent in patients with metastatic urinary transitional cell carcinoma? Ann Thorac Surg. 2011; 92: 449.

10. Svatek RS, Siefker-Radtke A, Dinney CP.: Management of metastatic urothelial cancer: the role of surgery as an adjunct to chemotherapy. Can Urol Assoc J. 2009; 3: 228.

11. Kanzaki R, Higashiyama M, Fujiwara A et al: Outcome of surgical resection of pulmonary metastasis from urinary tract transitional cell carcinoma. Interact Cardiovasc Thorac Surg 2010; 11: 60.

12. Otto $\mathrm{T}$, Krege $\mathrm{S}$, Suhr $\mathrm{J}$ et al: Impact of surgical resection of bladder cancer metastases refractory to systemic therapy on performance score: a phase II trial. Urology 2001; 57:55.

13. Zehnder P, Studer UE, Skinner EC et al: Super extended versus extended pelvic lymph node dissection in patients undergoing radical cystectomy for bladder cancer: a comparative study. J Urol 2011;186:1261.

14. Kondo $\mathrm{T}$, Nakazawa $\mathrm{H}$, Ito $\mathrm{F}$ et al Impact of the extent of regional lymphadenectomy on the survival of patients with urothelial carcinoma of the upper urinary tract. J Urol 2007;178:1212. 
Figure Legends

\section{Figure 1}

(a) Kaplan-Meier analysis of overall survival from the initiation of treatment for metastatic urothelial carcinoma.

(b) Kaplan-Meier analysis of overall survival from the time of metastasectomy.

(c) Kaplan-Meier analysis of overall survival from the time of metastasectomy for patients with solitary lung or solitary lymph node metastasis (-) compared with that of other patients (一). 
Figure 1.

(a)

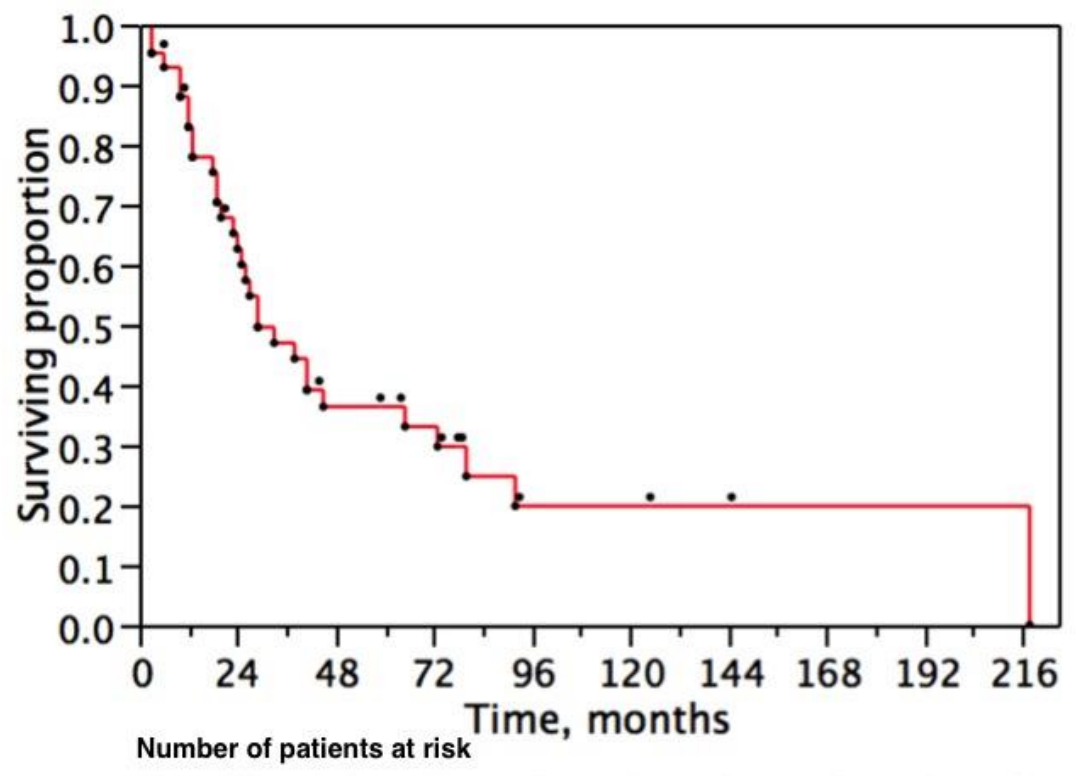

(b)

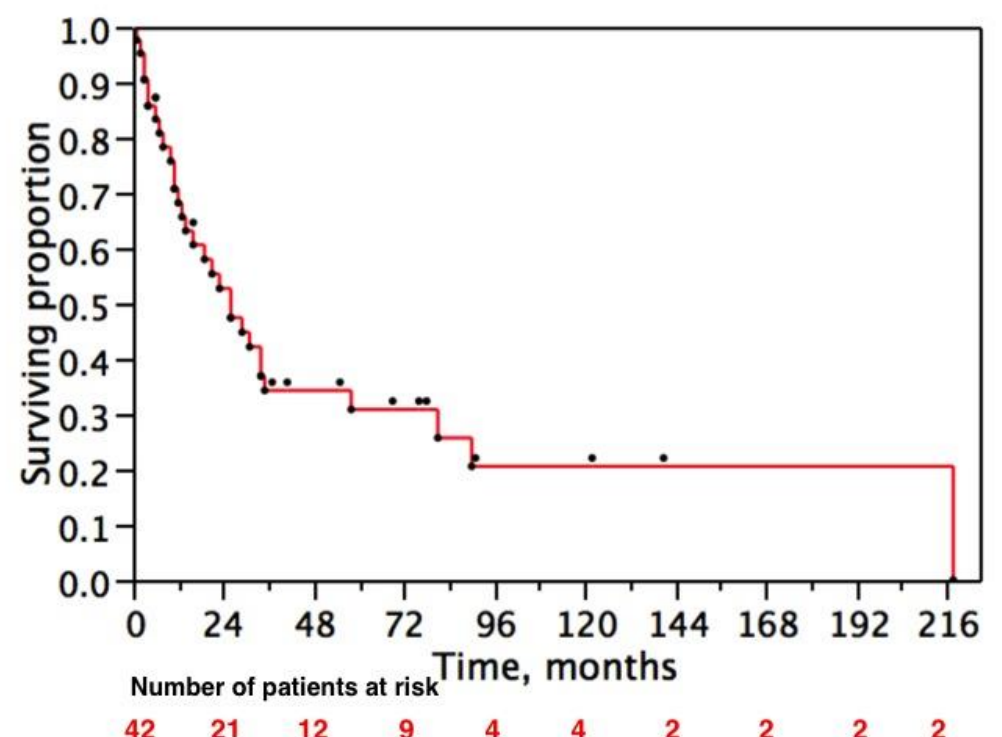


(c)

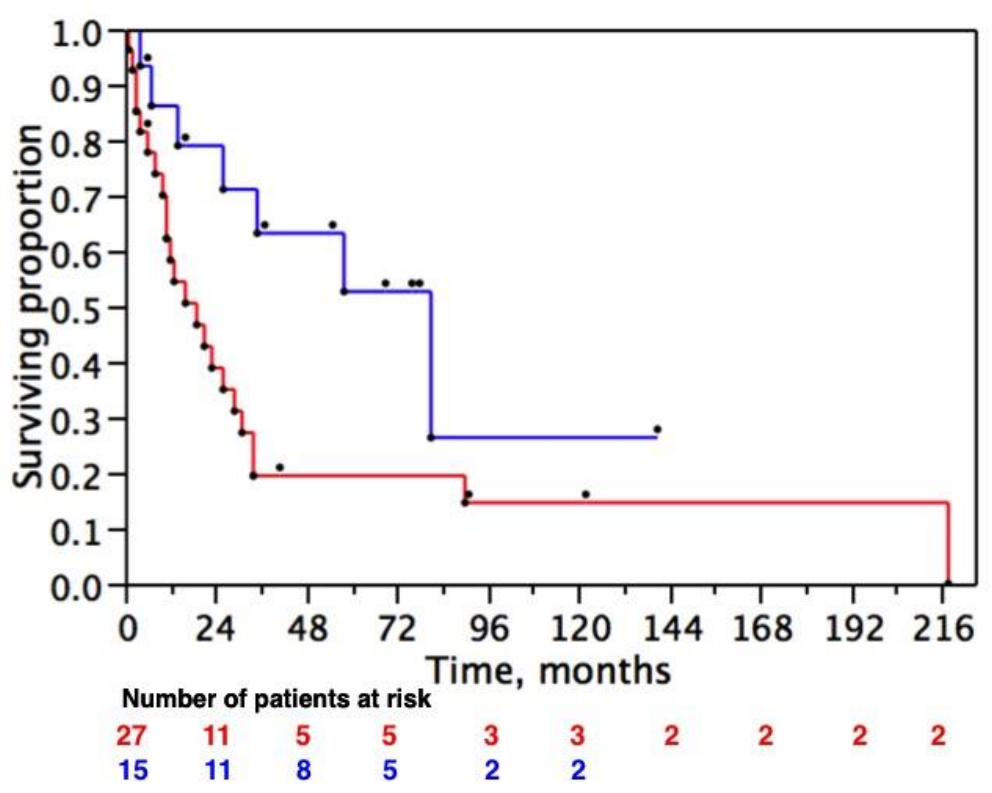


Table 1. Patients' characteristics.

\begin{tabular}{|c|c|}
\hline & $\mathrm{n}=42$ \\
\hline Age, years & median: 67.5 (range: $36-80$ ) \\
\hline \multicolumn{2}{|l|}{ Sex } \\
\hline male & 29 \\
\hline female & 13 \\
\hline \multicolumn{2}{|l|}{ Primary tumor site } \\
\hline bladder & 21 \\
\hline upper urinary tract & 18 \\
\hline both & 3 \\
\hline \multicolumn{2}{|l|}{ Metastatic sites* } \\
\hline regional LN recurrecnce & 8 \\
\hline distant LNs & 12 \\
\hline lung & 14 \\
\hline bone & 1 \\
\hline liver & 2 \\
\hline adrenal gland & 1 \\
\hline local recurrence & 5 \\
\hline \multicolumn{2}{|l|}{ No. of metastasis } \\
\hline 1 & 23 \\
\hline 2 or more & 14 \\
\hline uncountable $^{\dagger}$ & 5 \\
\hline $\begin{array}{l}\text { Disease-free interval between primary surgey } \\
\text { and development of metastases, month }\end{array}$ & median: 16 (range: 0-103) \\
\hline \multicolumn{2}{|l|}{ Treatment course } \\
\hline metastasectomy after chemotherapy & 34 \\
\hline chemotherapy after metastasectomy & 7 \\
\hline metastasectomy only & 1 \\
\hline Follow-up time, months & media: 28 (range: 3-218) \\
\hline Follow-up time from metastasectomy, months & median: 22 (range: 1-218) \\
\hline
\end{tabular}


Table 2. Chemotherapy regimens used by the present cohort.

\begin{tabular}{|l|c|}
\hline & No. of patients \\
\hline $\begin{array}{l}\text { MVAC (methotrexate, vinblastine, } \\
\text { adriamycin, cisplatin) }\end{array}$ & 19 \\
\hline $\begin{array}{l}\text { MEC (methotrexate, epirubicin, } \\
\text { cisplatin) }\end{array}$ & 9 \\
\hline $\begin{array}{l}\text { GC (gemcitabine, cisplatin) } \\
\text { Gemcitabine+carboplatin }\end{array}$ & 11 \\
\hline $\begin{array}{l}\text { Gemcitabine monotherapy } \\
\text { CISCA (cisplatin, cyclophosphamide, } \\
\text { adriamycin) }\end{array}$ & 4 \\
\hline $\begin{array}{l}\text { Any paclitaxel or docetaxel-including } \\
\text { regimen }\end{array}$ & 2 \\
\hline $\begin{array}{l}\text { Administration of at least 2 different } \\
\text { regimens }\end{array}$ & 21 \\
\hline
\end{tabular}


Table 3. Summary of metastasectomy.

\begin{tabular}{|l|c|}
\hline Procedure & \\
\hline Lymph node dissection & 6 \\
\hline Retroperitoneal lymph nodes below aortic bifurcation & 9 \\
\hline Retroperitoneal lymph nodes above aortic bifurcation & 5 \\
\hline Distant lymph nodes & 20 \\
\hline & 12 \\
\hline Pulmonary resection & 3 \\
\hline Exenteration & 2 \\
\hline Resection of local recurrence & 2 \\
\hline Resection of subcutaneous metastasis & 1 \\
\hline Liver resection & 1 \\
\hline Amputation of lower leg & 1 \\
\hline Adrenalectomy & \\
\hline & \\
\hline Pathology of metastasis & 30 \\
\hline Viable cells & 12 \\
\hline Necrosis & \\
\hline
\end{tabular}


Table 4. Results of univariate analysis of prognostic significance after metastasectomy.

\begin{tabular}{|c|c|c|c|}
\hline Factor & No. of patients & Median survival time, months $(95 \% \mathrm{Cl})$ & $P$-value \\
\hline \multicolumn{4}{|c|}{ (1) } \\
\hline Male & 29 & $26(11-34)$ & \\
\hline Female & 13 & 31 (8-not reached) & 0.2064 \\
\hline \multicolumn{4}{|l|}{ Age, years } \\
\hline$<68$ & 21 & $21(10-90)$ & \\
\hline$\geq 68$ & 21 & $29(13-81)$ & 0.9988 \\
\hline \multicolumn{4}{|l|}{ Primary site } \\
\hline Bladder only & 21 & 21 (10-not reached) & \\
\hline Others & 21 & $34(12-81)$ & 0.9713 \\
\hline \multirow{2}{*}{\multicolumn{4}{|c|}{$\begin{array}{l}\text { DFI between primary surgey and } \\
\text { development of metastases }\end{array}$}} \\
\hline & & & \\
\hline$<12$ & 17 & $23(11-58)$ & \\
\hline$\geq 12$ & 25 & $26(10-81)$ & 0.9077 \\
\hline$<24$ & 30 & $26(13-58)$ & \\
\hline$\geq 24$ & 12 & 26 (3-not reached) & \\
\hline \multicolumn{4}{|l|}{$\begin{array}{l}\text { Upfront chemotherapy before } \\
\text { metastasectomy }\end{array}$} \\
\hline Yes & 34 & $26(13-35)$ & \\
\hline No & 8 & 29 (1-not reached) & 0.9498 \\
\hline \multicolumn{4}{|l|}{ Metastatic sites } \\
\hline Lymph node only & 19 & 26 (13-not reached) & \\
\hline Lung only & 12 & $34(13-81)$ & \\
\hline Others & 11 & $11(3-29)$ & 0.2858 \\
\hline Lymph node or lung & 32 & $31(16-81)$ & \\
\hline Others & 10 & $11(1-29)$ & 0.1933 \\
\hline $\begin{array}{c}\text { Solitary lymph node } \\
\text { or solitary lung metastasis }\end{array}$ & 15 & 81 (14-not reached) & \\
\hline \multirow[t]{2}{*}{ Others } & 27 & $19(10-29)$ & 0.0296 \\
\hline & & DFl=disease-free interval & \\
\hline
\end{tabular}

